\title{
Thromkid - a Competence Network for Functional Platelet Abnormalities
}

\section{Results of a Population Based Survey Carried Out by the Pediatric Group of the German Society of Thrombosis and Hemostasis Research (GTH)}

\author{
Werner Streifa, Martin Olivieria, Stefan Weickardt ${ }^{\mathrm{b}}$ \\ for the THROMKID study group of the GTH \\ a Department of Pediatrics, Medical University Innsbruck, Austria \\ ${ }^{b}$ Department of Pediatrics, University Hospital Carl Gustav Carus Dresden, \\ ${ }^{c}$ Department of Pediatrics, Hospital Braunschweig, Germany
}

\section{Key Words}

Platelets · Platelet function tests · Platelet disorders .

Data collection

\section{Summary}

Background: Hereditary disorders of platelet function are often complex. Bleeding due to defective platelet function may be intermittent and unpredictable. Only few guidelines concerning testing for platelet function and treatment of affected patients have been developed so far. These experiences prompted the authors to initiate a collaborative patterns-of-practice survey and to establish a competence network in order to improve diagnosis and treatment of affected patients in German speaking countries (Thromkid quality project). Materials and Methods: Data were obtained by using standardized survey protocols between May 2005 and August 2006. Results: A total of 50 centers were identified. $88 \%$ agreed to participate in Thromkid. The laboratories offered a median of 4 tests. All laboratories offered platelet aggregometry. 28 laboratories used the PFA-100 ${ }^{\circledR}$ closure time. Further widely used tests were the in vivo bleeding time and flow cytometry. 215 affected patients were identified 123 of whom fulfilled the authors' set of criteria, $43 \%$ were considered poorly characterized. Morbus Glanzmann, aspirin-like defects, and receptor defects were the most common diagnoses. Discussion: Future activities include i) to establish a web-based register of all centers, ii) to establish a patient registry, and iii) to prepare the basis for well-designed clinical studies resulting in rational and clinically useful guidelines for diagnosis and treatment of affected patients.

\author{
Schlüsselwörter \\ Blutplättchen · Thrombozytenfunktion . \\ Thrombozytenfunktionsstörung · Datensammlung
}

\section{Zusammenfassung}

Hintergrund: Angeborene Störungen der Thrombozytenfunktion sind häufig komplexe Erkrankungen mit unterschiedlich stark ausgeprägter Blutungsneigung. Bis heute gibt es kaum Richtlinien für die Durchführung von Thrombozytenfunktionstests und die Behandlung von betroffenen Patienten. Diese Erfahrung veranlasste die Autoren zur Durchführung einer Umfrage in spezialisierten Zentren und zur Gründung eines Qualitätsnetzwerkes (Thromkid-Qualitätsprojekt), mit dem Ziel die Diagnosestellung und Behandlung betroffener Patienten im deutschen Sprachraum zu verbessern. Material und Methoden: Die Daten wurden mit Hilfe standardisierter Fragebögen zwischen Mai 2005 und August 2006 erhoben. Ergebnisse: Insgesamt konnten 50 Zentren identifiziert werden, von denen $88 \%$ zur Teilnahme an der Studie bereit waren. Alle Labors boten die Aggregometrie als wichtigste Methode an. 28 Labors verwendeten den PFA- $100^{\circledR}$. Weitere wichtige Methoden waren die Invivo-Blutungszeit und die Durchflusszytometrie. 215 betroffene Patienten konnten identifiziert werden, von denen 123 eine eindeutige Diagnose aufwiesen, bei $43 \%$ war die Diagnose unklar. Morbus Glanzmann, Aspirin-ähnliche Defekte und Rezeptordefekte waren die häufigsten Diagnosen. Diskussion: In Planung ist 1) die Anlage eines internetbasierten Registers aller Diagnose- und Behandlungszentren, 2) ein Patientenregister und 3) die Vorbereitung für die Durchführung von gut konzipierten klinischen Studien, die die Entwicklung von rationalen und sinnvollen Leitlinien zur Diagnose und Behandlung betroffener Patienten erlauben.

\begin{tabular}{ll}
\hline KARGER & @ 2007 S. Karger GmbH, Freiburg \\
$\begin{array}{l}\text { Fax +49 76145207 14 } \\
\begin{array}{l}\text { E-mail Information@Karger.de } \\
\text { www.karger.com }\end{array}\end{array}$ & $\begin{array}{l}\text { Accessible online at: } \\
\text { www.karger.com/tmh }\end{array}$
\end{tabular}




\section{Introduction}

Platelets are essential for normal hemostasis. They contain many structural, metabolic and signaling components, resulting in four interconnected mechanisms all of which promote hemostasis: i) adhesion to sites of vascular injury and to artificial surfaces, ii) release of compounds by granules, iii) aggregation in order to form a platelet plug, and iv) presentation of a procoagulant surface for activation of protein complexes of the coagulation cascade [1].

Hereditary disorders of platelet function are often complex, and some are not completely understood [2]. The hallmarks are mucocutaneous and gastrointestinal bleeding, menorrhagia, epistaxis, easy bruising and bleeding from the oral cavity. Defective platelet function must be severe for clinically important spontaneous bleeding to occur, and even with severe abnormalities, bleeding may be intermittent and unpredictable. However, blood loss after trauma and surgery may be severe and life threatening in these patients [3].
Only few guidelines concerning testing for platelet function and treatment of patients with hereditary disorders of platelet function have been developed and published so far $[4,5]$. To our knowledge, until now none of these efforts has resulted in widely accepted and clinical useful recommendations for the

Table 1. Questionnaire about laboratories and platelet function tests

General information about processing laboratory

General information about used tests

Detailed information on various aspects of test procedure and validation and interpretation of test results

Turbidimetric aggregometry, impedance aggregometry and luminometry PFA- $100^{\circledR}$ CT

In vivo bleeding time

Thrombelastography including ROTEM ${ }^{\circledR}$

Flow cytometry

Electron microscopy

Molecular genetic tests

Other rare tests of platelet function
Table 2. Diagnostic criteria for patients with hereditary disorders of platelet function

\begin{tabular}{|c|c|c|c|}
\hline \multirow[t]{2}{*}{ Disease } & \multicolumn{3}{|l|}{ Diagnostic criteria } \\
\hline & primary & secondary & Tertiary \\
\hline \multicolumn{4}{|l|}{ Defects of adhesion proteins } \\
\hline Morbus Glanzmann & $\begin{array}{l}\text { flow cytometry } \\
\text { molecular genetics }\end{array}$ & $\begin{array}{l}\text { aggregometry } \\
\text { blood smear }\end{array}$ & $\begin{array}{l}\text { PFA- } 100^{\circledR} \text { CT } \\
\text { in vivo bleeding time } \\
\text { thrombelastography } \\
\text { platelet count }\end{array}$ \\
\hline Bernard Soulier syndrome & $\begin{array}{l}\text { flow cytometry } \\
\text { molecular genetics }\end{array}$ & $\begin{array}{l}\text { aggregometry } \\
\text { blood smear }\end{array}$ & $\begin{array}{l}\text { PFA- } 100^{\circledR} \text { CT } \\
\text { in vivo bleeding time } \\
\text { thrombelastography } \\
\text { platelet count }\end{array}$ \\
\hline \multicolumn{4}{|c|}{ Secretion- and signal transduction defects } \\
\hline$\alpha$ - and/or $\delta$-Storage pool defects* & electron microscopy & $\begin{array}{l}\text { mepakrin test } \\
\text { luminometry } \\
\text { serotonin releasing } \\
\text { assay } \\
\text { flow cytometry }\end{array}$ & $\begin{array}{l}\text { PFA- } 100{ }^{\circledR} \text { CT } \\
\text { in vivo bleeding time } \\
\text { platelet count } \\
\text { aggregometry } \\
\text { blood smear } \\
\text { thrombelastography }\end{array}$ \\
\hline Aspirin-like defects & $\begin{array}{l}\text { enzymatic defect } \\
\text { assay }\end{array}$ & $\begin{array}{l}\text { aggregometry } \\
\text { PFA-100 }{ }^{\circledR}-\mathrm{CT} \\
\text { malondialdehyde } \\
\text { assay }\end{array}$ & $\begin{array}{l}\text { platelet count } \\
\text { in vivo bleeding time } \\
\text { flow cytometry }\end{array}$ \\
\hline
\end{tabular}

Receptor defects

Collagen, $\alpha 2$-adrenergic, TXA 2 receptor defects flow cytometry

aggregometry

blood smear

PFA- $100{ }^{\circledR}$ CT

microscopy

in vivo bleeding time thrombelastography platelet count

MYH9 macrothrombopenia

Fechtner syndrome, May-Hegglin anomaly molecular genetics

blood smear / microscopy

platelet count immuno histochemistry

*Including Hermansky-Pudlak syndrome. 
Table 3. Platelet function tests performed by participating laboratories

Number of

laboratories

Aggregation and adhesion

Turbidimetric aggregometry

Impedance aggregometry

Platelet adhesion assays*

34

4

Platelet secretion

Luminometry

Serotonin secretion assay

5

Global platelet function

PFA- $100^{\circledR} \mathrm{CT}$

28

Flow cytometry-based platelet function tests $\quad 26$

In vivo bleeding time

Platelet metabolism

Malondialdehyde assay

Clot formation

Thrombelastography including ROTEM ${ }^{\circledR}$

Clot retraction test

Morphology of platelets

Electron microscopy

Molecular genetic methods

3

* DiaMed Impact-R test, Adeplat, adhesion measurement on various surfaces.

diagnosis and treatment of these patients. In addition, personal communications with clinical experts in the field revealed a considerable number of patients with bleeding symptoms, which are highly suggestive for disorders of primary hemostasis that are not sufficiently characterized up to now.

These experiences prompted the authors together with other members of the pediatric group of the GTH to initiate a collaborative patterns-of-practice survey and to establish a competence network in order to improve diagnosis and treatment of patients with functional platelet abnormalities.

The goals of Thromkid are i) to obtain information on the evaluation of hereditary disorders of platelet function in clinical laboratories, ii) to collect information on patients diagnosed with or suffering from symptoms highly suggestive for hereditary disorders of platelet function, iii) to establish a web-based register of all centers offering diagnostic tests and/or expert patient care for patients with hereditary disorders of platelet function, iv) to establish a registry for patients with hereditary disorders of platelet function, and v) to prepare the basis for well-designed clinical studies resulting in rational and clinical useful guidelines for diagnosis and treatment of these patients.

We report on the first results of Thromkid, based on the sur- vey carried out between May 2005 and August 2006. A general overview and an outlook on future perspectives and activities of the Thromkid study group are presented.

\section{Materials and Methods}

Thromkid data acquisition was carried out between May 2005 and August 2006. All senior investigators of the Thromkid study group are members of the pediatric group of the GTH. All investigators are specialized in clinical hemostasis. They aim to improve diagnosis and treatment of coagulation disorders preferentially in German speaking countries.

Centers for diagnosis and treatment of patients with hereditary disorders of platelet function were identified by personal communication with members of the GTH and by contacting local staff members of these identified centers and asking for further coagulation laboratories and treatment centers in their area.

Diagnostic centers were defined as facilities providing various platelet function tests. Laboratories offering exclusively the PFA- $100{ }^{\circledR}$ closure time (CT) (Dade-Behring, Marburg, Germany) and/or in vivo bleeding time were not considered as centers. Treatment centers were defined as facilities that provide continuous medical care for patients with well established diagnosis of hereditary disorders of platelet function.

Study survey protocols included a variety of questions addressing diagnosis and treatment and other disease-related aspects of patients suffering from hereditary disorders of platelet function, or of patients presenting with symptoms highly suggestive for a diagnosis of hereditary disorders of platelet function (table 1). Table 2 summarizes diagnostic criteria that were applied by the authors. Depending on the suspected diagnosis, a set of primary, secondary and tertiary criteria was obligatory for acceptance of diagnosis.

Data were obtained by using standardized protocols. Interviews were carried out by personnel previously trained by senior investigators. All identified centers were visited and underwent an audit procedure. All data were critically appraised by senior investigators. Conflicts were solved by re-contacting local members of each center.

The study was approved by the institutional research ethics board requirements (MUI UN2436, 235/4.3).

\section{Results}

A total of 50 centers in Austria, Germany, Switzerland and Alto Adige (German-speaking part of former Tyrol, Italy) were identified. 44 centers $(88 \%)$ agreed to participate in Thromkid. Figures 1 and 2 specify the centers. $22 \%$ of the centers were certified according to various commonly accepted quality requirements.

The laboratories offered a variety of tests with a median of 4 tests per laboratory. All laboratories offered platelet aggregometry and its variants. 28 laboratories assessed platelet function using the PFA-100 CT. The PFA-100 CT was frequently used as screening method in combination with aggregometry. Another widely used test was the in vivo bleeding time $(\mathrm{n}=19)$. Morbus Glanzmann and Bernard Soulier syndrome were preferentially diagnosed or ruled out by flow cytometry. Aggregometry, PFA-100, CT, in vivo bleeding time, and flow cytometry turned out to be the most trusted methods in diagnosis of patients with hereditary platelet disorders. 


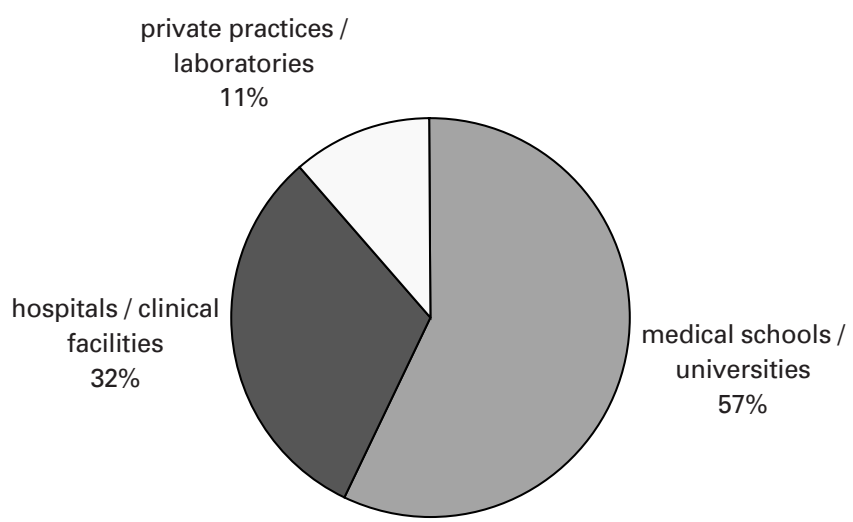

Fig. 1. Characterization of centers offering platelet function tests 1 .

215 patients with suspected hereditary disorders of platelet function were identified. 123 patients fulfilled the authors' set of criteria outlined in table 2. M. Glanzmann, aspirin-like defects, receptor defects, storage pool defects, and Bernard Soulier syndrome were the most common diagnoses (fig. 3). In collaboration with the members of GTH, the authors developed information sheets for each center (fig. 4). These will be published on the official webpage of the GTH.

\section{Discussion}

Hereditary disorders of platelet function are a heterogeneous group of diseases with a predominantly mild or moderate bleeding tendency $[3,6]$. Bleeding may be severe and difficult to control in case of trauma, surgery, and other situations which challenge the hemostatic system. Due to technical difficulties, time-consuming test procedures and the short survival time of platelets after venipuncture, most platelet function tests are restricted to highly specialized laboratories, resulting in potential under-diagnosis of these diseases.

Personal experience of the authors and communication with other colleagues in the field, who have had similar experiences, prompted the authors to initiate a collaborative survey and to establish a competence network in order to improve diagnosis and treatment of patients with functional platelet abnormalities.

Thromkid is a quality project of the pediatric group of the GTH. The core of this study is a collaborative patterns-ofpractice survey intended to overview diagnosis and treatment of patients with functional platelet abnormalities in Germanspeaking countries. These data will form the cornerstone of a new competence network that will address various diagnosisand treatment-related questions. The overall goal is to improve diagnosis and treatment of these patients.

A total of 50 centers were identified by the investigators. $88 \%$ agreed to cooperate. Not unexpected, most centers were em-

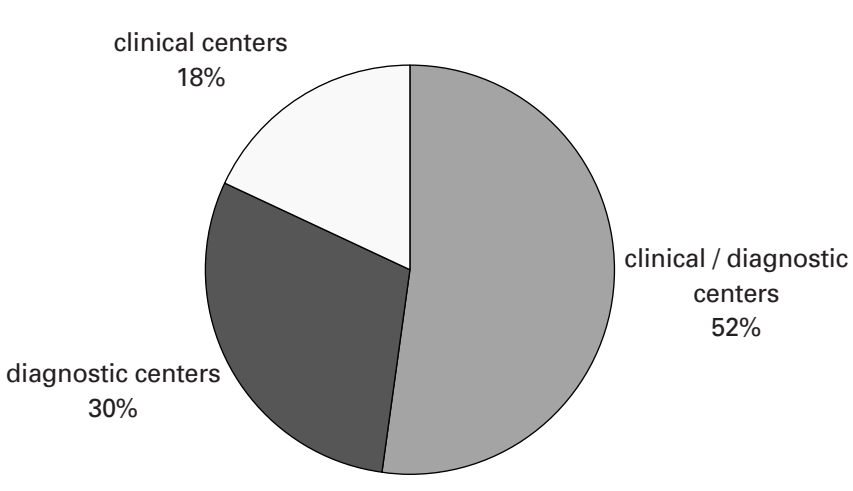

Fig. 2. Characterization of centers offering platelet function tests 2 .

bedded in universities and medical schools. 36 clinical laboratories offered a wide variety of tests. In accordance with practical considerations, laboratories offered a set of tests (median 4 tests). Platelet counts and assessment of blood smears were standard procedures in all laboratories. Detailed descriptions of these, without any doubt, very useful tests are beyond the scope of this paper. Aggregometry, PFA-100 CT, in vivo bleeding time, and flow cytometry were the most frequently applied platelet function tests. Although introduced more than 40 years ago, aggregometry was by far the most commonly performed platelet function test. The Moffat et al. [7] survey of the North American Specialized Coagulation Laboratory Association (NASCOLA) revealed similar results. The in vivo bleeding time is still the only routine test that may assess most aspects of hemostasis, including platelet function, coagulation and vessel wall function [8]. In vivo bleeding time played an important role in screening for defects of primary hemostasis in clinical laboratories participating in our study. This may be explained at least in part by the fact that the majority of centers combined in vivo bleeding time with careful physical examination of the patient and clinical assessment of bleeding symptoms. Many specialists in hemostasis, especially those practicing in the UK and USA, consider in vivo bleeding time a cumbersome test with poor reproducibility [9]. Over the last years, the PFA-100 CT, also often addressed as in vitro bleeding time, has replaced in vivo bleeding time in many laboratories. Restricted to screening investigations, the PFA-100 CT may facilitate fast identification of patients with von Willebrand disease and some platelet function disorders in clinical settings [4]. Flow cytometry allows testing for membrane glycoprotein deficiencies, such as M. Glanzmann (CD41/61) and Bernard Soulier syndrome $(\mathrm{CD} 42 \mathrm{~b} / 42 \mathrm{a} / 42 \mathrm{~d})$ with very small sample sizes [10]. Since these important hereditary disorders of platelet function disorders (which frequently present with severe bleeding symptoms) can safely be diagnosed by flow cytometry, 26 centers have adopted this method. Due to the time-consuming 
Fig. 3. Diagnoses of 215 patients with suspected hereditary disorders of platelet function.

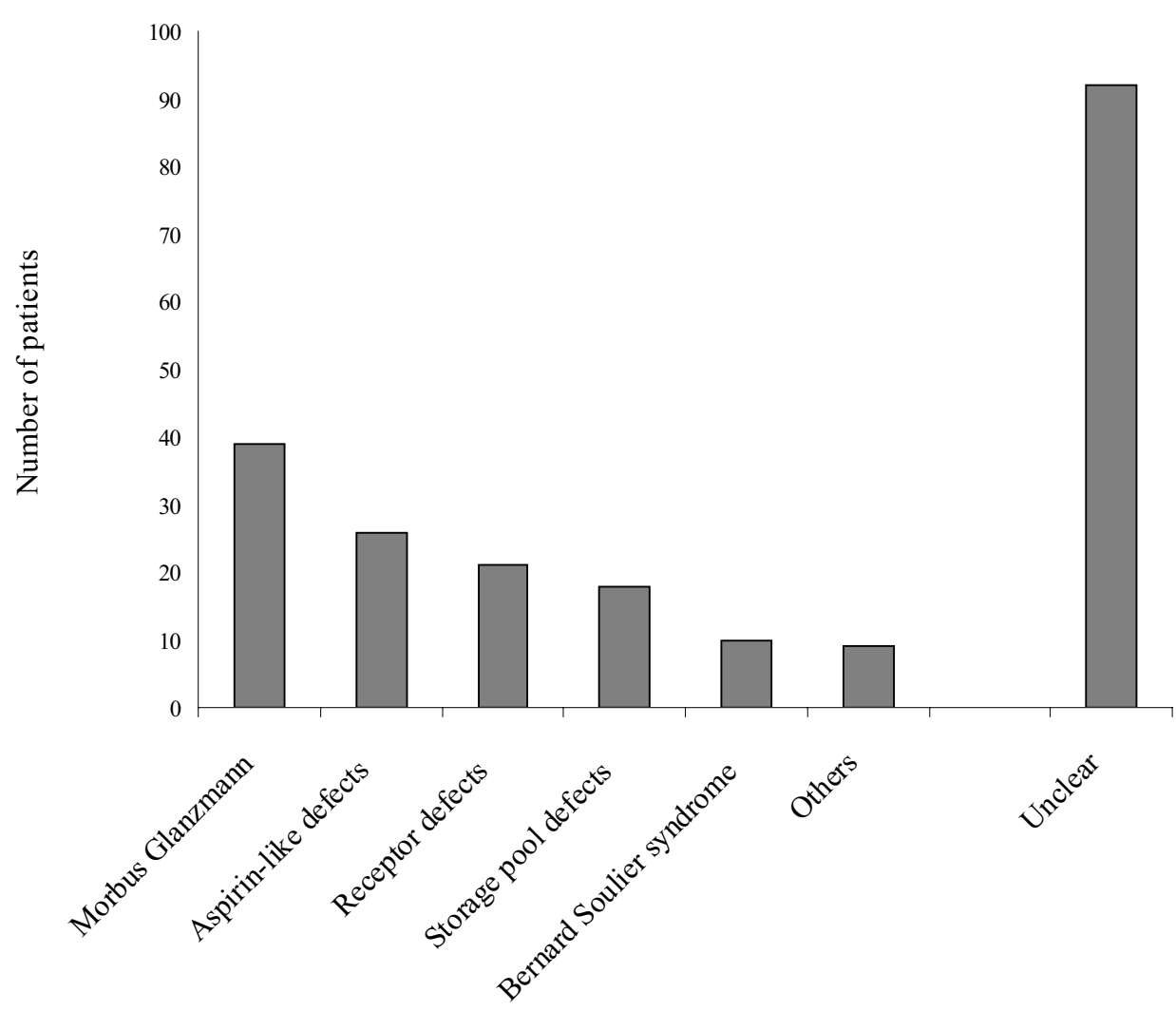

and difficult method, in our study flow cytometry was only used as second line test in order to confirm or exclude suspected defects of platelet membrane glycoproteins.

However, most routinely applied test sets were likely to miss various hereditary platelet disorders, especially those with mild and moderate bleeding tendency. In addition, mild and moderate bleeding tendency often puts little pressure on responsible physicians. Compared to other diseases, diagnostic assessment of patients with hereditary platelet defects is sometimes difficult and time-consuming or even impossible. In our study, $57 \%$ of patients were sufficiently characterized following the criteria proposed by the authors (table 2). M. Glanzmann that is associated with moderate to severe bleeding tendency, was the most frequent diagnosis. The local frequency of rarer diagnoses often appeared to be dependent on the availability of testing methods resulting in potential underdiagnosis of many platelet disorders. In the light of these findings, it is not surprising that $43 \%$ of patients had an unclear diagnosis even though bleeding symptoms and some laboratory findings where highly suggestive for platelet disorders (fig. 3). Diagnosis of inherited disorders of platelet function will always need careful history and clinical examination of the patients in question. Laboratory results can only confirm or rule out clinical suspicion.

At least some of these undiagnosed or poorly characterized patients may directly profit from a competence network reducing the effort necessary for responsible physicians to find and contact highly specialized centers. Publication of data sheets addressing all frequently asked questions concerning diagnostic and treatment centers (fig. 4) will be published soon on the official society webpage of the GTH (www.gthonline.org).

Only recently registries for hemophilia, the classic bleeding disorder, have been started in Germany and Austria. The relatively high number of hemophiliacs, the clear therapeutical concept with coagulation factor administration together with the burden of high treatment costs for the communities certainly have contributed to the early establishment of these registries. Although some registries, including www.orpha.net in France and www.med.mssm.edu/glanzmanndb in the USA, collect data on M. Glanzmann, no general non-profit registry for patients with hereditary disorders for platelet function exists. The European organization of rare diseases (www.eurordis.org) including www.orpha.net may play a role in collection and distribution of information from and for these patients in the future. A registry may be the cornerstone to allow for developing of evidence-based criteria for diagnosis and treatment of patients with hereditary platelet function disorders. Although many questions have not yet been answered, Thromkid has collected enough data to initiate a patient registry. Well designed multicenter trials are urgently needed to develop treatment options for these patients.

The data from the Thromkid survey demonstrate the difficulties for clinical laboratories to diagnose patients with hereditary platelet disorders. Moreover, platelet test sets varied 
Fig. 4. Example of future information sheet accessible through webpage of the GTH www. gthonline.org.

\section{Medizinische Universität Innsbruck}

Department für Kinder- und Jugendheilkunde

MEDIZINISCHE UNIVERSITAT INNSBRUCK

\author{
Verantwortlicher Arzt/Ärztin: Univ. Prof. Dr. Werner Streif \\ Verantwortlicher Laborassistent/in: MTA Christian Reif \\ Kontakt: \\ Anichstraße 35 \\ A- 6020 Innsbruck
}

Tel. $+43512504-23600$

Fax +43 512 504-23484

DECT Handy (Prof. Streif) +43 51250481182

DECT Handy (Herr Reif) +4351250480995

@werner.streif@uibk.ac.at

@ christian.reif@uibk.ac.at

Internetseite: www.i-med.ac.at mw.gerinnung.at

Angebot diagnostischer Verfahren zur Bestimmung der Thrombozytenfunktion:

- Blutungszeit

- $P F A 100^{\circledR}$

- Turbidimetrische Aggregometrie

- Lumiaggregometrie

- Thrombelastogramm

- Durchflußzytometrie

- Elektronenmikroskopie

Zertifizierung: ISO 9002 widely between laboratories. Consequently, under-diagnosis may jeopardize patients' lives in the case of emergency bleeding. Further research should focus on the development of con- sensus guidelines for diagnostic tests and treatment options for these patients. The Thromkid competence network has the potential to fulfill these needs. 


\section{Acknowledgments}

We thank the entire THROMKID Investigative Team (contributors listed in 'Appendix'), medical technical personal and all others that have made valuable contributions to this study. The authors are indebted to N. Jones for his contribution to the study and his English assistance. Novo-Nordisk generously covered travel expenses.

\section{Appendix}

Participating centers in alphabetical order:

Augsburg: W. Behr and P. Heidemann (Klinikum Augsburg, Zentrallabor, Klinik für Kinder- und Jugendheilkunde, Deutschland), Basel: T. Kühne and German Marbet (Universitätskinderspital, Hämatologisches Labor; Kantonsspital Basel, Hämostaselabor DZL, Schweiz), Berlin: K. Seeger and O. Meyer (UK Charité Campus Virchow Klinikum, Klinik für Kinder- und Jugendmedizin, Institut für Transfusionsmedizin, Berlin, Deutschland), R. Klamroth (Krankenhaus Friedrichshain, Berlin, Deutschland), Bonn: B. Pötzsch and U. Harbrecht (Universitätsklinikum Bonn, Institut für Experimentelle Hämatologie und Transfusionsmedizin, Deutschland), Bozen: M. Svaldi (KH Bozen, Hämatologisches Labor, Italien), Braunschweig: W. Eberl (Klinikum Braunschweig, Klinik für Kinder- und Jugendmedizin, Deutschland), Bremen: G. Auerswald and A. Weidenhammer (Prof. Hess-Kinderklinik, Deutschland), Chemnitz: A. Hofmann and A. Liebert (Klinikum Chemnitz, Klinik für Kinder- and Jugendmedizin, Institut für Laboratoriumsmedizin, Deutschland), Cottbus. E. Holfeld and R. Munke (Carl-Thiem-Klinikum,, Klinik für Kinder- and Jugendmedizin, Institut für Klinische Chemie and Labordiagnostik, Deutschland), Dresden: R. Knöfler and G. Siegert (Universitätsklinikum der TU Dresden, Klinik für Kinder- and Jugendmedizin, Institut für Klinische Chemie and Laboratoriumsmedizin, Deutschland), Duisburg: H. Trobisch, S. Halimeh and G. Kappert (Labor Trobisch, Duisburg, Deutschland), Düsseldorf: H.J. Laws (Heinrich-Heine Universität, Klinik für Pädiatrische Hämatologie and Onkologie, Deutschland), Frankfurt/ M.: W. Kreuz, C. Escuriola-Ettingshausen (Johann-Wolfgang-Goethe Universität, Klinik für Kinder- and Jugendmedizin), Frankfurt/O.: A. Nimtz-Talaska (Praxis für Gerinnungsstörungen, Deutschland), Greifswald: A. Greinacher and S. Weigel (Ernst-Moritz-Arndt-Universität, Institut für Immunologie and Transfusionsmedizin, Klinik für Kinder- und Jugendmedizin, Deutschland), Halle/Saale: R. Schobeß and A. Heider (Martin-Luther-Universität, Klinik für Kinder- und Jugendmedizin, Zentrallabor, Deutschland), Hamburg: R. Schneppenheim, K. Beutel and G. Marx (Universitätskrankenhaus Eppendorf, Klinik für Kinder- und Jugendmedizin, Institut für Klinische Chemie/Zentrallaboratorien, Deutsch- land), U. Budde (Labor Dr. Keeser/ Prof. Arndt und Partner, Deutschland), Hannover: C. Wermes and L. Grote (Medizinische Hochschule Hannover, Zentrum für Kinder- und Jugendmedizin, Hämostaseologisches Labor der Klinik für Hämatologie, Hämostaseologie und Onkologie, Deutschland), F. Bergmann (Ärztliche Partnerschaft Wagner Stibbe, Deutschland ), Heidelberg: A. Huth-Kühne (Kurpfalzkrankenhaus Heidelberg, Deutschland), Homburg: U. Hübner (Universitätsklinikum des Saarlandes, Institut für Klinische Hämostaseologie und Transfusionsmedizin, Deutschland), Innsbruck: W. Streif (Medizinische Universität Innsbruck, Department für Kinder- und Jugendheilkunde, Österreich), Jena: K. Kentouche, D. Schmidt and W. Lösche (Friedrich-Schiller Universität, Klinik für Kinder- und Jugendmedizin, Institut für Klinische Chemie und Laboratoriumsdiagnostik, Klinik für Anästhesiologie und Intensivtherapie, Deutschland), Köln: R. Röhling (Klinikum der Universität zu Köln, Klinik und Poliklinik für Allgemeine Kinderheilkunde, Deutschland), Leipzig: H. Lenk (Universität Leipzig, Klinik und Poliklinik für Kinderund Jugendmedizin, Deutschland), A. Siegemund (Labor Dr. ReisingAckermann und Partner, Deutschland), Linz: J. Tomasits (AKH Linz, Zentrallabor, Österreich), Lübeck: S. Gutsche and I. Dörges (Universitätsklinikum Schleswig-Holstein, Klinik für Kinder- und Jugendmedizin, Zentrales Hämatologie- und Gerinnungslabor der Medizinischen Klinik, Deutschland), Magdeburg: V. Aumann and K. Hartung (Universitätsklinikum Magdeburg, Klinik für Kinder- und Jugendmedizin, Institut für Klinische Chemie und Pathobiochemie, Deutschland), München: K. Kurnik (Ludwig-Maximilians-Universität, Dr. von Haunersches Kinderspital, Deutschland), Münster: U. Nowak-Göttl and R. Mesters (Westfälische Wilhelms Universität, Klinik und Poliklinik für Kinder- und Jugendmedizin, Zentrallabor, Deutschland), B. Kehrel (Klinik für Anästhesiologie, Experimentelle und Klinische Hämostaseologie Münster, Deutschland), Regensburg: C.M. Schambeck (Universitätsklinikum Regensburg, Zentrallabor, Deutschland), Rostock: U. Kyank, C. Burstein and V. Kiefel (Universität Rostock, Klinik für Kinder- und Jugendmedizin, Institut für Klinische Chemie und Laboratoriumsmedizin, Abteilung für Transfusionsmedizin, Deutschland), Salzburg: N. Jones, J. Unger (LKH Salzburg; Kinderspital, Zentrallabor, Österreich), Schlanders: G. Gios (KH Schlanders Abt. f. Pädiatrie, Italien), St. Gallen: J. GreinerLang and W. Korte (Kantonsspital St. Gallen, Ostschweizer Kinderspital, Klinische Chemie and Hämatologie, Schweiz), Tübingen: R. Rauch, G. Wiegand, K. Jaschonek, P. Gawaz (Universitätsklinikum Tübingen, Klinik für Kinder- and Jugendmedizin, Medizinische Klinik Abteilung II und III, Deutschland), Wien: C. Male and M. Minkow (AKH Wien; Universitätsklinik für Kinder und Jugendheilkunde, St. Anna Kinderspital, Österreich), Wiesbaden: C.M. Kirchmaier and D. Westrup (DKD Wiesbaden, Hämatologisches Labor, Deutschland), Zürich: M. Schmugge (Kinderspital Zürich, Hämatologisches Labor, Schweiz)

\section{References}

1 George JN, Colman RW: Overview of Platelet structure and function; in Colman RW, Marder VJ, Clowes AW, George JN, Goldhaber SZ (eds): Hemostasis and Thrombosis. Basic Principles and Clinical Practice. Philadelphia, Lippincott Williams and Wilkins, 2006, pp 437-441.

2 Hayward CP, Rao AK, Cattaneo M: Congenital platelet disorders: overview of their mechanisms, diagnostic evaluation and treatment. Haemophilia 2006;12(suppl 3):128-136.

3 Cattaneo M: Inherited platelet-based bleeding disorders. J Thromb Haemost 2003;1:1628-1636.
4 Hayward CP, Harrison P, Cattaneo M, Ortel TL, Rao AK: Platelet function analyzer (PFA)-100 closure time in the evaluation of platelet disorders and platelet function. J Thromb Haemost 2006;4: 312-319.

$\checkmark 5$ The British Society for Haematology BCSH Haemostasis and Thrombosis Task Force: Guidelines on platelet function testing. J Clin Pathol 1988;41:1322-1330.

6 Nurden AT, Nurden P: Inherited disorders of platelets: an update. Curr Opin Hematol 2006;13: 157-162.
7 Moffat KA, Ledford-Kraemer MR, Nichols WL, Hayward CP: Variability in clinical laboratory practice in testing for disorders of platelet function: results of two surveys of the North American Specialized Coagulation Laboratory Association. Thromb Haemost 2005;93:549-553.

8 Sutor AH: The bleeding time in pediatrics. Semin Thromb Hemost 1998;24:531-543.

9 Rodgers RP, Levin J: A critical reappraisal of the bleeding time. Semin Thromb Hemost 1990; 16:1-20.

10 Linden MD, Frelinger AL, III, Barnard MR, Przyklenk K, Furman MI, Michelson AD: Application of flow cytometry to platelet disorders. Semin Thromb Hemost 2004;30:501-511. 